\title{
Equity in the delivery of health care: Some international comparisons*
}

\author{
Eddy van Doorslaer
}

Erasmus University, Rotterdam, Netherlands

\author{
Adam Wagstaff** \\ University of Sussex, Brighton, UK
}

Final version received July 1992

This paper presents the results of an eight-country comparative study of equity in the delivery of health care. Equity is taken to mean that persons in equal need of health care should be treated the same, irrespective of their income. Two methods are used to investigate inequity: an index of inequity based on standardized expenditure shares, and a regression-based test. The results suggest that inequity exists in most of the eight countries, but that there is no simple one-to-one correspondence between a country's delivery system and the degree to which persons in equal need are treated the same.

\section{Introduction}

In a companion paper in this issue [Wagstaff, Van Doorslaer et al. (1992)], we presented evidence on cross-country differences in health care financing systems and in the progressivity characteristics of these systems. We argued that analysing separately equity in the finance of health care and equity in the delivery of health care was warranted, given that academics and policy-makers alike appear to accept that different distributional principles ought to apply in each case. Broadly speaking, it appears to be accepted that health care ought to be financed according to ability to pay but delivered according to 'necd'. Hence our concern in the companion paper with progressivity in health care finance.

Correspondence to: Adam Wagstaff, School of Social Sciences, Arts Building, University of Sussex, Falmer, Brighton BN1 9QN, UK.

*We are grateful to the European Community's COMAC-Health Services Research Committee, which funded the coordination of the project whose results are reported in this paper, to Tony Culyer, Karen Davis, Jacques van der Gaag, Bob Haveman, Jeremy Hurst, Julian Le Grand, Jean-Pierre Poullier and Alan Williams for helpful comments on the research underlying this paper, and to Brigitte Kerbusch, Caroline Verboom and Jan van Emmerik for their assistance in the organization of the project.

**And others. A full list of these authors and their affiliations appears in the appendix. 
In the present paper we examine equity in the delivery of health care, focussing on the horizontal version of the principle of distribution according to need: the requirement that persons in equal need ought to be treated the same. In common with most previous studies in this field, we search for violations of this principle that are related to income. We seek to establish, in other words, whether persons in equal need are treated the same irrespective of their income, or whether, as is often argued to be the case, the better-off receive more favourable treatment within each need category. ${ }^{1}$ We also seek to assess whether some countries come closer to achieving horizontal equity than others, and, if so, what features of health care systems seem to promote equity in the delivery of health care and which features seem to hinder its attainment.

The remainder of the paper is organized as follows. Section 2 outlines the principal differences in the health care delivery system of the eight countries included in the present study which appear likely to influence the extent to which persons in equal need are treated the same. Section 3 considers the problems associated with measuring equity in the delivery of health care. Section 4 outlines the data sources and the variable definitions. Section 5 presents the empirical results. The final section contains a summary and draws various conclusions.

\section{Equity and cross-country differences in health care delivery}

Our concern in this section is not to provide an exhaustive description of cross-counîry differences in health care delivery systems, but rather to outline the features which might be expected to influence the extent to which persons in equal need of health care are treated the same, irrespective of their income. It seems reasonable to suppose that the degree of income-related inequity associated with any health care delivery system is likely to depend in part on the extent to which the incomes of consumers affect their health-related behaviour and in part on the extent to which consumers' incomes affect the behaviour of health care providers.

The influence of income on the individual's own behaviour is likely to be greater the larger are the various financial and non-financial costs associated with making the initial contact with the health care sector and with receiving medical care once the initial contact has been made. Such costs are sometimes termed 'access costs' [Le Grand (1982), Mooney (1983)], though the term is potentially confusing, since many of the costs associated with the receipt of health care are incurred after the individual has gained access to

\footnotetext{
${ }^{1}$ In a recent Note in this Journal, Mooney et al. (1991) argue that, by focussing on the treatment that people receive, rather than on their access to treatment, empirical work of the type reported in this paper 'miss[es] the target'. For a defence of the treatment-based approach, see Culyer et al. (1992a). See also Mooney et al. (1992) and Culyer et al. (1992b).
} 
the health care system. The costs in question include out-of-pocket payments, transport costs and the opportunity cost of time spent travelling and waiting. The magnitude of these access costs may well vary with income, as may the effects of such costs.

Variation in insurance cover is one reason why access costs may themselves vary across income groups. Some idea of within-country variation in insurance cover in each of the eight countries can be gleaned from table 1 . In most countries insurance cover does not vary with income. In some countries, though, notably Ireland and the Netherlands, it is the better-off who have limited public cover. The U.S. stands out as the only country where a substantial proportion of persons on low incomes have no insurance cover whatsoever. Davis (1993) reports that in 1986, 37 million Americans ( $15 \%$ of the U.S. population) had no insurance cover. One-third had incomes below the official poverty line. All, however, were either insufficiently poor to qualify for Medicaid or failed to meet other entry criteria (most working-age men and adults without children are ineligible). The high out-of-pocket payments required to receive medical care appear to have deterred persons in this group from seeking medical carc. Out-of-pocket payments may also vary across income groups (see table 1). Although this typically involves persons on lower incomes being exempted from public sector co-payments, there are countries (Denmark is an example) where the less well-off end up making larger out-of-pocket payments because they have not taken out insurance cover against co-payments.

Other financial and non-financial barriers are also likely to be important and may also vary across income groups. The less well-off are likely to have to spend longer travelling to health care facilities than the well-off, being more reliant on public transport and tending to live in areas where health care resources are relatively scarce [Le Grand (1982)]. They are also likely to spend longer waiting in the waiting room, being less likely to have a telephone at home with which to make an appointment. The less well-off are also likely to spend longer on any waiting list, being less likely than the welloff to be able to 'go private', thereby bypassing any queue in the public sector. As is evident from table 1, sizeable proportions of the populations of Ireland, Italy, Spain and the U.K. have private insurance which generally ensures easier access.

But even if utilization costs were invariant with respect to income, the effects of these costs would be likely to vary. Even if, for example, the nominal value of out-of-pocket payments were the same for everyone, the sacrifice in terms of forgone utility (and hence the deterrent effect) would probably be greater for the persons on low incomes than for persons towards the top of the income distribution. Evidence from the RAND health insurance experiment in the U.S. suggests that this is indeed the case. Ncwhouse, Manning and Morris (1981) remarked that 'Our interim results 

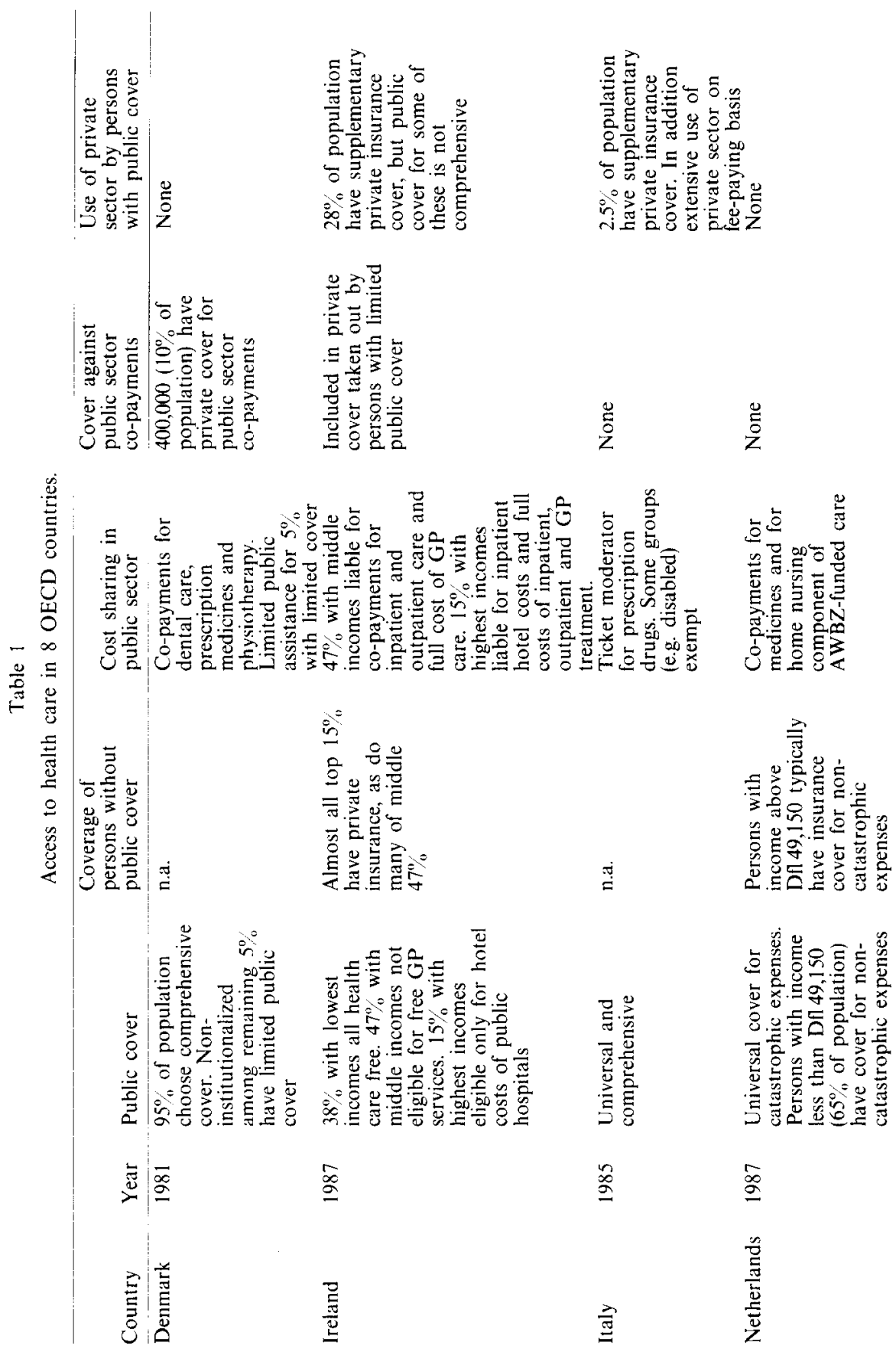

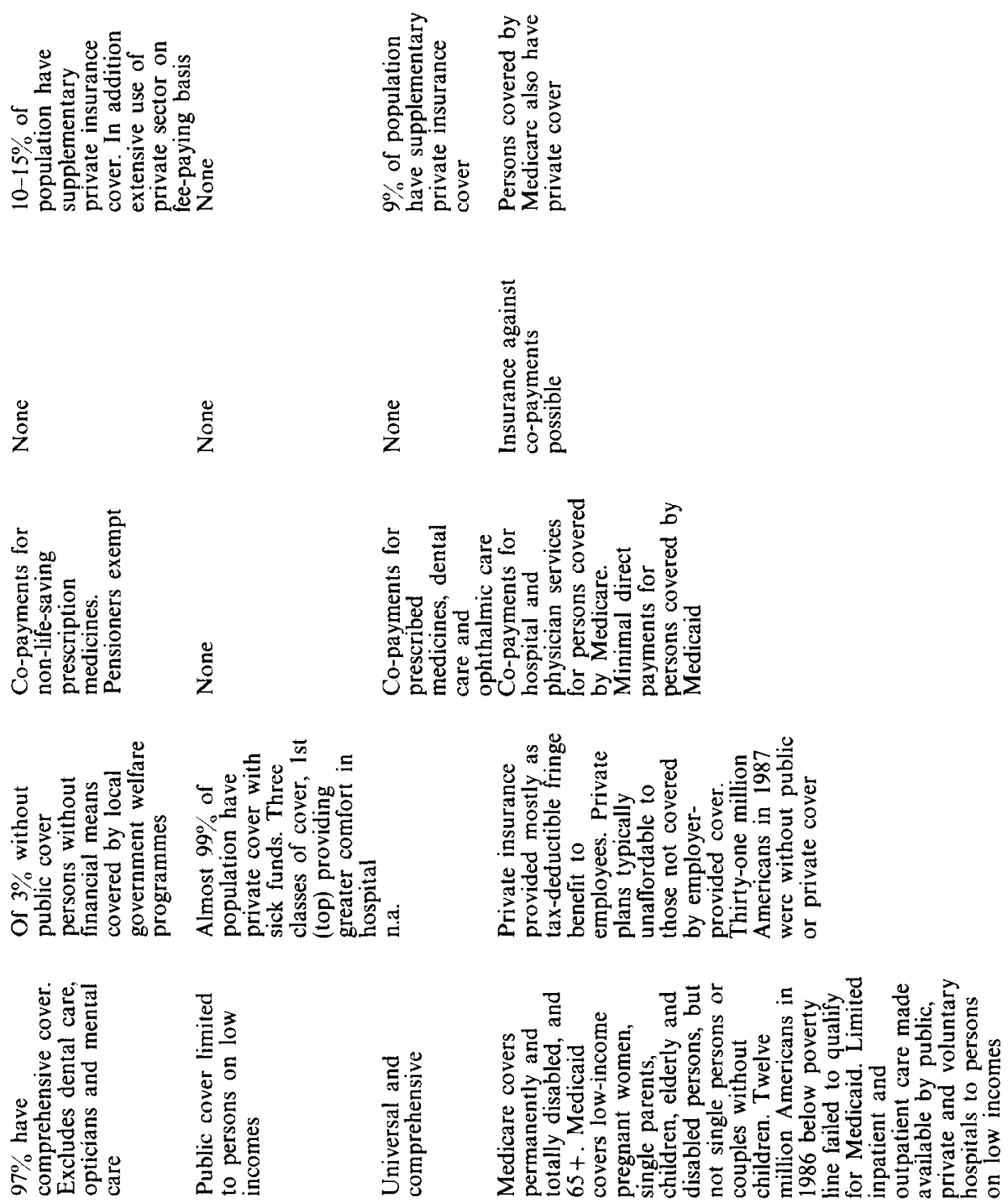

$\stackrel{\check{\alpha}}{\circ}$

$\underset{\alpha}{\alpha}$

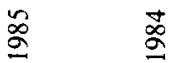

章

苞

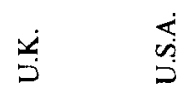


Table 2

Anti-equity provider incentives.

\begin{tabular}{|c|c|c|c|}
\hline Country & Year & Ambulatory care & Inpatient care \\
\hline Denmark & 1981 & None & None \\
\hline Ireland & 1987 & $\begin{array}{l}\text { Higher fees for private patients } \\
\text { than public patients }\end{array}$ & $\begin{array}{l}\text { Hospitals paid prospective } \\
\text { budgets for publicly insured but } \\
\text { FFS for privately insured and } \\
\text { publicly insured paying out-of- } \\
\text { pocket }\end{array}$ \\
\hline Netherlands & 1987 & $\begin{array}{l}\text { GPs and specialists paid } \\
\text { capitation for sick fund patients } \\
\text { but FFS for private patients }\end{array}$ & $\begin{array}{l}\text { Higher fees for private patients } \\
\text { than public patients }\end{array}$ \\
\hline Spain & 1987 & $\begin{array}{l}\text { Specialists paid salary for public } \\
\text { patients and FFS for private } \\
\text { patients }\end{array}$ & $\begin{array}{l}\text { Private hospitals paid per diem by } \\
\text { State and retrospectively by } \\
\text { private insurance companies. } \\
\text { Public sector physicians paid } \\
\text { salary. } \\
\text { Private sector physicians paid } \\
\text { FFS }\end{array}$ \\
\hline Switzerland & 1981 & $\begin{array}{l}\text { Physicians can charge higher fees } \\
\text { for persons with } 1 \text { st and } 2 \text { nd class } \\
\text { insurance cover }\end{array}$ & None \\
\hline U.K. & 1985 & None prior to 1991 reforms & $\begin{array}{l}\text { NHS doctors paid salary for NHS } \\
\text { patients and FFS for private } \\
\text { patients. Full-time NHS } \\
\text { consultants limited in amount } \\
\text { they can earn from private } \\
\text { practice, but part-time not limited }\end{array}$ \\
\hline U.S.A. & 1984 & $\begin{array}{l}\text { Less generous reimbursement for } \\
\text { Medicaid patients than others }\end{array}$ & $\begin{array}{l}\text { Less generous reimbursement for } \\
\text { Medicaid patients than others }\end{array}$ \\
\hline
\end{tabular}

indicate that the poor are not more responsive to cost sharing if the cost sharing is less for low income families, as in the experiment. However, our results do indicate that cost sharing unrelated to income would differentially affect lower income families' (p. 1505 emphasis added).

The link between provider incentives and patient income is likely to be important in determining how close a health care system comes to achieving 'equal treatment for equal need'. The most obvious way that the income of a patient might influence provider behaviour is if the provider is paid differently depending on whether the patient is being treated publicly or privately. As is clear from table 2 , in several countries some providers are paid in such a way that providing care to private patients is more profitable than providing care to public patients. Physicians, for example, may be paid on a fee-for-service basis for private patients, but by salary and/or capitation for public patients. Hospitals may receive a prospective budget for public patients but receive a fee for private patients. That such arrangements may well result in persons on different incomes but in equal need being treated differently is suggested by the work of Hooijmans and Rutten (1984). They 
examined regional differences in the Netherlands in the hospital utilization of (high income) privately insured and (low income) publicly insured, and found that - after controlling for other factors - specialist density had a positive influence on private hospital use but no effect on public hospital use. They interpreted this finding to be a consequence of the fact that the fees for treating private patients were twice those for treating public patients.

\section{Measurement of inequity in the delivery of health care}

A moment's reflection ought to reveal that a simple comparison of the average amount of treatment received by different income groups reveals nothing about whether or not persons in equal need are or are not being treated the same, since 'need' (typically proxied in empirical work by selfreported hcalth status) tends to be correlated with income. Thus, for example, the fact that the well-off privately insured in the Netherlands tend to have fewer GP contacts than the less well-off publicly insured ${ }^{2}$ indicates nothing about any inequity in the Dutch health care delivery system, since the privately insured tend to be in better health than the publicly insured. This suggests that an assessment of equity in the delivery of health care ought to be based on treatment differentials adjusted for differences in 'need'.

\subsection{Testing for inequity}

The tests of inequity employed in the project, and the reasons for adopting them rather than other tests, have been set out elsewhere in this Journal. ${ }^{3}$ Here we present only a brief summary.

Suppose there are two income groups, which we shall call 'rich' and 'poor', and two illness categories, ill and not ill. Let $m_{i}$ be the medical expenditure received by person $i$, and $h_{i}$ be a dummy taking a value of 1 if person $i$ is ill and zero otherwise. Suppose for the moment that medical expenditures are generated according to the model

$$
m_{i}= \begin{cases}\alpha_{\mathrm{p}}+\beta_{\mathrm{p}} h_{i}+u_{\mathrm{p} i} & \text { if poor } \\ \alpha_{\mathrm{r}}+\beta_{\mathrm{r}} h_{i}+u_{\mathrm{r} i} & \text { if rich }\end{cases}
$$

where $\alpha_{p}$ and $\alpha_{r}$ indicate the expected medical expenditures received by a

\footnotetext{
${ }^{2} \mathrm{Cf}$. e.g. Van Vliet and Van de Ven (1985).

${ }^{3}$ See Wagstaff et al. (1991a). See also O'Donnell and Propper (1991a), Le Grand (1991), O'Donnell and Propper (1991b), and Wagstaff et al. (1991b).
} 
poor non-sick person and a rich non-sick person, respectively, and $\alpha_{\mathrm{p}}+\beta_{\mathrm{p}}$ and $\alpha_{\mathrm{r}}+\beta_{\mathrm{r}}$ indicate the expected medical expenditures received by a poor sick person and a rich sick person, respectively. The hypothesis that persons in the same degree of need receive the same treatment, irrespective of their income, can be tested by testing the hypothesis that $\alpha_{\mathrm{p}}=\alpha_{\mathrm{r}}$ and $\beta_{\mathrm{p}}=\beta_{\mathrm{r}}$. This can be done either by estimating separate equations for each income group or by using dummy income variables to construct an equivalent single equation model. Thus suppose that $y_{i}$ is a dummy variable taking a value of 1 if person $i$ is rich and 0 otherwise. Then eq. (1) is equivalent to the single equation model

$$
m_{i}=\pi_{0}+\pi_{1} y_{i}+\pi_{2} h_{i}+\pi_{3} y_{i} \cdot h_{i}+u_{i}
$$

where $\pi_{0}=\alpha_{\mathrm{p}}, \pi_{1}=\alpha_{\mathrm{r}}-\alpha_{\mathrm{p}}, \pi_{2}=\beta_{\mathrm{p}}$ and $\pi_{3}=\beta_{\mathrm{r}}-\beta_{\mathrm{p}} \cdot{ }^{4}$ Estimating eq. (2) and testing the hypothesis that $\pi_{1}=\pi_{3}=0$ is equivalent to estimating eq. (1) and testing the hypothesis that $\alpha_{\mathrm{p}}=\alpha_{\mathrm{r}}$ and $\beta_{\mathrm{p}}=\beta_{\mathrm{r}}$.

The approach above can easily be extended to allow for several income groups and for several need indicators. Demographic factors, which have been ignored hitherto, can also be incorporated. Thus let $x_{i}$ be a dummy variable taking a value of one if person $i$ is elderly. Then a more plausible model to eq. (1) is:

$$
m_{i}= \begin{cases}x_{\mathrm{p}}+\beta_{\mathrm{p}} h_{i}+\delta_{\mathrm{p}} x_{i}+u_{\mathrm{p} i} & \text { if poor } \\ \alpha_{\mathrm{r}}+\beta_{\mathrm{r}} h_{i}+\delta_{\mathrm{r}} x_{i}+u_{\mathrm{r} i} & \text { if rich, }\end{cases}
$$

so that a poor person who is both healthy and young is expected to receive an amount of expenditure equal to $\alpha_{p}$, while his elderly counterpart is expected to receive an amount of expenditure equal to $\alpha_{p}+\delta_{p}$. Rich and poor will be treated alike within all age-morbidity categories if and only if $\alpha_{r}=\alpha_{p}$, $\beta_{\mathrm{r}}=\beta_{\mathrm{p}}$ and $\delta_{\mathrm{r}}=\delta_{\mathrm{p}}$.

The approach can also easily accommodate the fact that, in a typical distribution of medical expenditures, a large percentage of the population records zero utilization. An appropriate regression model in this case is a two-part model, the first part of which models the determinants of the individual's decision to seek care, whilst the second models the determinants of the amount of care received, given that a contact has been made. ${ }^{5}$ The first part can be estimated as logit or probit models and the second part can then be estimated by OLS using only those individuals recording positive utilization. The hypothesis of no inequity can then be tested using a likelihood ratio test, on a two-part version of either eq. (1) or eq. (2), bearing

${ }^{4}$ Eq. (2) is similar to the equation estimated by Puffer (1986) in his analysis of inequity in the delivery of health care in the U.K. and U.S.

${ }^{5}$ See, for example, Manning et al. (1981) and Van Vliet and Van de Ven (1985). 
in mind that the log-likelihood for a two-part model is the sum of the log-likelihoods of the two parts of the model. ${ }^{6}$

\subsection{Quantifying inequity}

The discussion of the previous section was concerned with testing for inequity. It does not enable inequity to be quantified - something that is essential if cross-country comparisons are to be performed. The regression approach can, however, be extended to allow an index of inequity to be derived, providing one is prepared to accept a more general definition of horizontal equity. ${ }^{7}$ So far, equity has been taken to mean that the intercepts and slope coefficients in the medical utilization equations should be the same for all income groups, i.e., in the case of eq. (1), $\alpha_{\mathrm{r}}=\alpha_{\mathrm{p}}$ and $\beta_{\mathrm{r}}=\beta_{\mathrm{p}}$. In other words a health care delivery system cannot be said to be horizontally equitable if the rich and poor are treated differently in any morbidity category. But what if the rich are treated favourably in one morbidity category (e.g. the non-sick category) but the poor are treated favourably in the other (e.g. the sick category)? A less restrictive definition of equity would regard such a situation as horizontally equitable on balance, providing any favourable treatment afforded to the poor amongst the sick was sufficiently large to offset the favourable treatment afforded to the rich amongst the nonsick. But how large does 'sufficiently large' have to be before one can say that, on balance, no inequity exists?

The present study measures inequity by reference to standardized expenditure figures [cf. Van Vliet and Van de Ven (1985)]. These values, which can be interpreted as the expenditures each income group would receive if it had the age distribution and the morbidity of the population as a whole, can be computed using the direct standardization method or regression analysis. If ordinary least squares (OLS) is used, the two methods are equivalent and the standardized expenditures of the rich and poor respectively in the model in eq. (1) can be defined as

$$
\begin{aligned}
& m_{\mathrm{r}}^{+}=a_{\mathrm{r}}+b_{\mathrm{r}} h \\
& m_{\mathrm{p}}^{+}=a_{\mathrm{p}}+b_{\mathrm{p}} h,
\end{aligned}
$$

\footnotetext{
${ }^{6}$ Using eq. (1) one would estimate separate two-part models for each income group and then estimate the same model for the entire sample. Using eq. (2) one would estimate a two-part model (with interaction terms) for the entire sample, first with the relevant $\pi$ 's unrestricted and then again with the same coefficients restricted to be zero. In both approaches twice the difference between the two models' likelihood values is distributed with a chi-squared distribution under the null hypothesis with as many degrees of freedom as there are parameters that are restricted in the restricted model [cf. e.g. Godfrey (1988)].

${ }^{7}$ What follows draws heavily on Wagstaff et al. (1991a).
} 


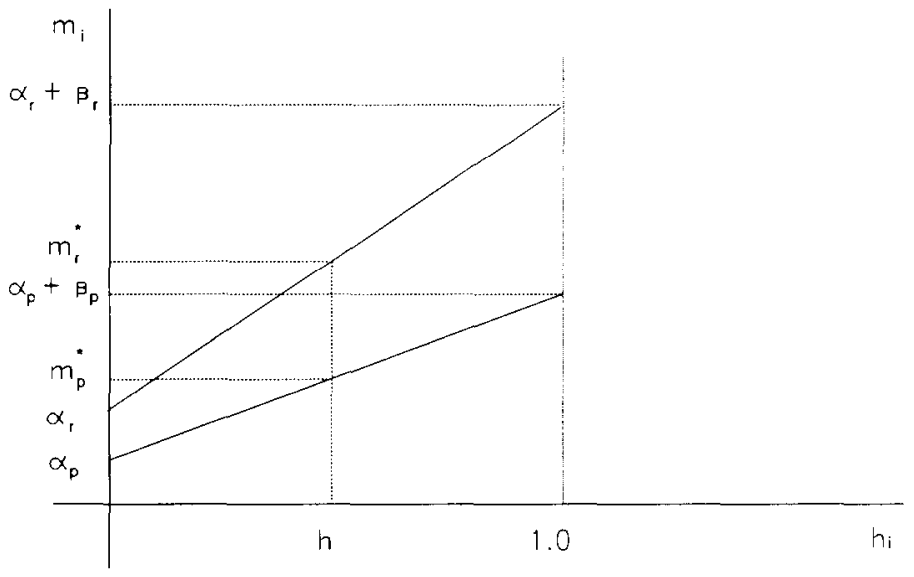

Fig. 1. Horizontal inequity in delivery of health care.

where $a_{\mathrm{r}}$ is the OLS estimate of $\alpha_{\mathrm{r}}, b_{\mathrm{r}}$ is the OLS estimate of $\beta_{\mathrm{r}}$, and so on, and $h$ is the sample mean of $h_{i}$.

We assess the extent of any inequity by looking at the difference between $m_{\mathrm{r}}^{+}$and $m_{\mathrm{p}}^{+}$(see fig. 1). This difference can be written

$$
m_{\mathrm{r}}^{+}-m_{\mathrm{p}}^{+}=\left(a_{\mathrm{r}}-a_{\mathrm{p}}\right)+h\left(b_{\mathrm{r}}-b_{\mathrm{p}}\right) \text {. }
$$

In this decomposition, the degree of inequity affecting a given morbidity category is weighted by the fraction of the population in that category. Thus the cntirc population is affected by any differences in the $\alpha$ 's, whilst only the sick (a fraction $h$ of the population) are affected by a discrepancy in the $\beta$ 's. Saying that inequity exists if $m_{\mathrm{r}}^{+} \neq m_{\mathrm{p}}^{+}$, and that it favours the rich if $m_{\mathrm{r}}^{+}>m_{\mathrm{p}}^{+}$, seems reasonable. It is evidently more general than the earlier definition of inequity (viz. $\alpha_{\mathrm{r}}=\alpha_{\mathrm{p}}$ and $\beta_{\mathrm{r}}=\beta_{\mathrm{p}}$ ), but subsumes it as a special case: if $\alpha_{\mathrm{r}}=\alpha_{\mathrm{p}}$ and $\beta_{\mathrm{r}}=\beta_{\mathrm{p}}$, it follows automatically that $(\mathrm{A})+(\mathrm{B})=0$. That it is more general can be seen from fig. 2 , which shows a situation where $\alpha_{\mathrm{r}}<\alpha_{\mathrm{p}}$ (inequity favours the poor amongst the non-sick) and $\beta_{\mathrm{r}}>\beta_{\mathrm{p}}$ (inequity favours the rich amongst the sick), and yet according to this more general definition of inequity there is, on balance, no inequity (i.e. $m_{\mathrm{r}}^{+}=m_{\mathrm{p}}^{+}$).

To obtain some idea of the extent of inequity one could, of course, simply compute standardized expenditure figures for each income group, using either the direct standardization method or regression analysis (ideally a twopart model), and then compare the values for the top and bottom groups. A more reliable approach is to plot a standardized expenditure concentration 


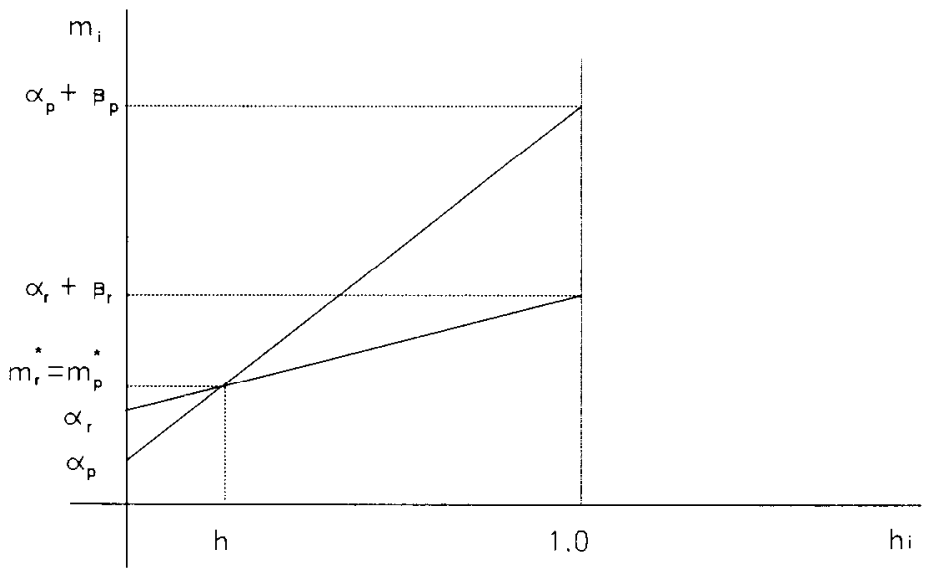

Fig. 2. Horizontal equity in delivery of health care.

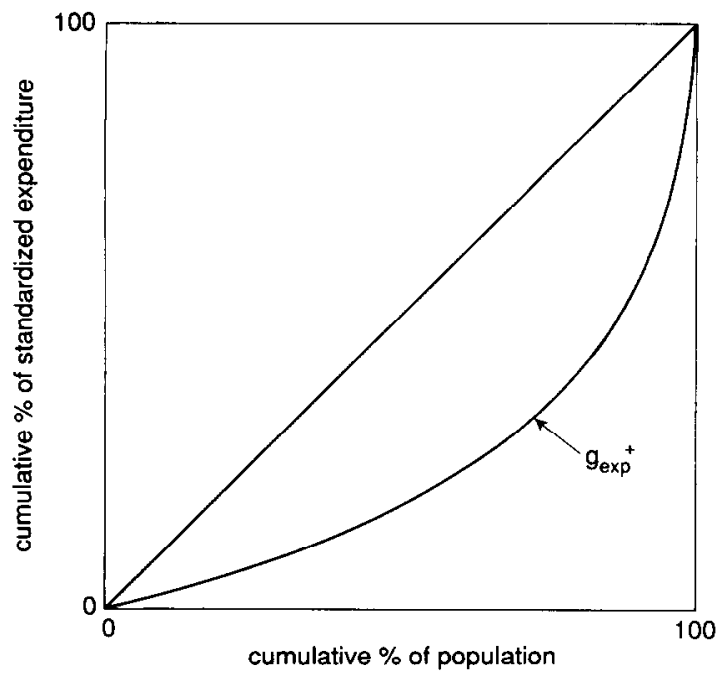

Fig. 3. Standardized expenditure concentration curve.

curve. This involves calculating standardized expenditure shares for each income group and then plotting the cumulative proportions of the population - ranked according to income - against their standardized expenditure shares. This is the curve labelled $g_{\exp }^{+}$in fig. 3. If there is, on balance, inequity 
favouring the rich, $g_{\exp }^{+}$will lie below the diagonal (the case illustrated), whilst the opposite will be true if there is inequity favouring the poor.

The extent of horizontal inequity can be measured by the concentration index corresponding to $g_{\text {exp }}^{+}$, denoted below by $\mathrm{HI}_{\mathrm{WVP}}$ [cf. Wagstaff et al. (1991a)]. This is defined as the ellipse-shaped area between $g_{\text {exp }}^{+}$and the diagonal, expressed as a proportion of the area under the diagonal. In the case where $g_{\exp }^{+}$lies above the diagonal (i.e. where there is inequity favouring the poor), the concentration index is defined as the negative of the ellipseshaped area as a proportion of the area under the diagonal. Thus $\mathrm{HI}_{\mathrm{WvP}}$ is negative when there is inequity favouring the poor (the lower bound being -1 ), and is positive when there is inequity favouring the rich (the upper bound being +1 ).

It is worth noting that $g_{\exp }^{+}$can cross the diagonal. In such cases the $\mathrm{HI}_{\mathrm{wvP}}$ index could register a value of zero even if the standardized expenditures vary across income groups. This would happen if the area between the concentration curve and the $45^{\circ}$ line lying to the left of the crossover point were equal to the corresponding area to the right of the crossover. Such a situation might arise, for example, if the top and bottom incomc groups both have standardized expenditure figures that are above those of the middle groups. The implicit value judgement involved in using the $\mathrm{HI}_{\mathrm{wvP}}$ index in this case is that inequity favouring one income group can offset inequity favouring another.

\section{Data and variable definitions}

Analysing equity in the delivery of health care calls for data at the individual level on whichever variable is used to rank individuals (equivalent income in the present study), morbidity (our measure of 'need') and utilization. In most countries the obvious source of such data is a health interview survey (cf. table 3 ). ${ }^{8}$ Only Britain and Ireland lack such surveys; in both cases a more general-purpose household interview survey has been used.

One shortcoming of health interview surveys (and a potential advantage of the more general-purpose surveys) is that their information on income and household structure can be somewhat limited. The Italian survey, for example, contained no information on the size and age structure of the

\footnotetext{
${ }^{8}$ Two other countries, France and Portugal, also participated in this comparative study of health care delivery systems. The results for these countries were excluded from the present paper, since the health indicators available were insufficiently comparable to those used by the other eight countries. The French and Portuguese results are reported in Lachaud and Rochaix (1993) and Pereira and Pinto (1993).
} 
Table 3

Data sources for analysis of delivery systems.

\begin{tabular}{|c|c|c|c|c|c|}
\hline Country & Abbr. & Year & Survey & $\begin{array}{l}\text { Institution } \\
\text { conducting } \\
\text { survey }\end{array}$ & $\begin{array}{l}\text { Sample } \\
\text { size } \\
\text { (persons) }\end{array}$ \\
\hline Denmark & DK & $1982 / 3$ & Danish Health Study & Odense University & 3,153 \\
\hline Ireland & IRL & 1987 & SIDPUSS & ESRI & 8,310 \\
\hline Italy & I & 1985 & $\begin{array}{l}\text { Health Care } \\
\text { Consumption Survey }\end{array}$ & $\begin{array}{l}\text { Centro Europa } \\
\text { Ricerche }\end{array}$ & 2,197 \\
\hline Netherlands & NL & $1981 / 2$ & $\begin{array}{l}\text { Health Interview } \\
\text { Survey }\end{array}$ & CBS & 10,319 \\
\hline Spain & $\mathrm{E}$ & 1987 & $\begin{array}{l}\text { National Health } \\
\text { Survey }\end{array}$ & INE & 16,770 \\
\hline Switzerland & $\mathrm{CH}$ & $1981 / 2$ & $\begin{array}{l}\text { SOMIPOPS and } \\
\text { SEVS surveys }\end{array}$ & $\begin{array}{l}\text { National Science } \\
\text { Foundation }\end{array}$ & 3,835 \\
\hline UK & UK & 1985 & $\begin{array}{l}\text { General Household } \\
\text { Survey }\end{array}$ & $\mathrm{CSO}$ & 25,000 \\
\hline USA & US & 1980 & NMCUES & $\begin{array}{l}\text { National Center for } \\
\text { Health Statistics }\end{array}$ & 10,396 \\
\hline
\end{tabular}

respondent's family, which meant that individuals in the Italian results are ranked by family income rather than equivalent income. ${ }^{9}$

Blaxter (1989) has proposed a useful schema for classifying morbidity measures according to the underlying conceptual model. She distinguishes between: (i) a medical model, in which ill-health is defined in terms of a deviation from physiological norms; (ii) a social-interactional or functional model, in which ill-health is defined in terms of a lack of ability to perform 'normal' tasks or roles; and (iii) a subjective model, in which ill-health is defined in terms of the individual's perception. She then suggests how the various morbidity measures that crop up in health interview surveys fit into this schema: questions about chronic illness are argued to derive from the medical model; questions asking whether the individual's normal activities were affected by ill-health in the recall period are argued to derive from the functional model; questions on self-assessed health (e.g. 'Do you consider your health to be good, quite good, or not good?') are argued to derive from the subjective model. Most countries' surveys contain questions deriving from each of Blaxter's models. There are, however, some exceptions, as is apparent from table 4. In the American survey, for example, there is no question such as 'Do you have any long-standing health problem or chronic illness?' All but the Irish survey contain information on functional health limitations and a question on self-assessed health along the lines 'Do you consider your health in general to be excellent, good, fair or poor?'.

Utilization has been measured by imputed expenditures, as in Le Grand's

${ }^{9}$ Different equivalence scales were used in each country's results. 
Table 4

Morbidity indicators available.

\begin{tabular}{|c|c|c|c|}
\hline Country & Medical model & Functional model & Subjective model \\
\hline Denmark & $\begin{array}{l}\text { Chronic illness (yes/no). } \\
\text { No. of chronic illnesses }\end{array}$ & $\begin{array}{l}\text { No. restricted-activity } \\
\text { days. } \\
\text { No. bed-days }\end{array}$ & $\begin{array}{l}\text { Health defined as 'not } \\
\text { good' if respondent } \\
\text { disagreed with statement } \\
\text { 'My health is excellent' }\end{array}$ \\
\hline Ireland & Chronic illness (yes/no) & & \\
\hline Italy & Chronic illness (yes/no) & $\begin{array}{l}\text { Limiting chronic illness } \\
\text { (yes/no). } \\
\text { Restricted-activity days } \\
\text { (yes/no) }\end{array}$ & $\begin{array}{l}\text { Three categories in self- } \\
\text { assessment: good, quite } \\
\text { good or not good. Latter } \\
\text { used to define health 'not } \\
\text { good' }\end{array}$ \\
\hline Netherlands & Chronic illness (yes/no) & $\begin{array}{l}\text { Restricted-activity days } \\
\text { (yes/no) }\end{array}$ & $\begin{array}{l}\text { Four categories in self- } \\
\text { assessment: good, } \\
\text { sometimes good/ } \\
\text { sometimes bad, fair, poor. } \\
\text { Bottom } 3 \text { used to define } \\
\text { health 'not good' }\end{array}$ \\
\hline Spain & $\begin{array}{l}\text { List of } 26 \text { conditions } \\
\text { later classified by } \\
\text { principal components } \\
\text { analysis into chronic } \\
\text { and other }\end{array}$ & $\begin{array}{l}\text { Limiting chronic illness } \\
\text { (yes/no). } \\
\text { Restricted-activity days } \\
\text { (yes/no) }\end{array}$ & $\begin{array}{l}\text { Four categories in self- } \\
\text { assessment: very good, } \\
\text { good, fair, not good. } \\
\text { Latter used to define } \\
\text { health 'not good' }\end{array}$ \\
\hline Switzerland & $\begin{array}{l}\text { Physician-diagnosed } \\
\text { chronic condition } \\
\text { (yes/no) }\end{array}$ & $\begin{array}{l}\text { Limiting chronic illness } \\
\text { (yes/no) }\end{array}$ & $\begin{array}{l}\text { Four categories in self- } \\
\text { assessment: excellent, } \\
\text { good, fair, poor. Bottom } \\
\text { two used to define health } \\
\text { "not good" }\end{array}$ \\
\hline U.K. & Chronic illness (yes/no) & $\begin{array}{l}\text { Limiting chronic illness } \\
\text { (yes/no) }\end{array}$ & $\begin{array}{l}\text { Three categories in self- } \\
\text { assessment: good, fairly } \\
\text { good or not good. Latter } \\
\text { used to define health "not } \\
\text { good' }\end{array}$ \\
\hline U.S.A. & & $\begin{array}{l}\text { Limiting chronic illness } \\
\text { (yes/no) }\end{array}$ & $\begin{array}{l}\text { Four categories in self- } \\
\text { assessment: excellent, } \\
\text { good, fair, poor. Latter } \\
\text { used to define health 'not } \\
\text { good' }\end{array}$ \\
\hline
\end{tabular}

(1978) study. Thus in contrast to studies such as that of Collins and Klein (1980), the present study takes into account not just whether an individual contacted the health care sector but also how much care was received. Moreover, in contrast to studies such as that of Puffer (1986), the present study includes not just primary care, but also specialist care and inpatient care. Dental care has been excluded on the grounds that the measures of need used do not, on the whole, reflect dental health. Medicines (prescribed and OTC) were also excluded, since several surveys did not include sufficiently detailed information to allow expenditures to be imputed. In arriving at overall imputed expenditure, GP visits, specialist visits and 


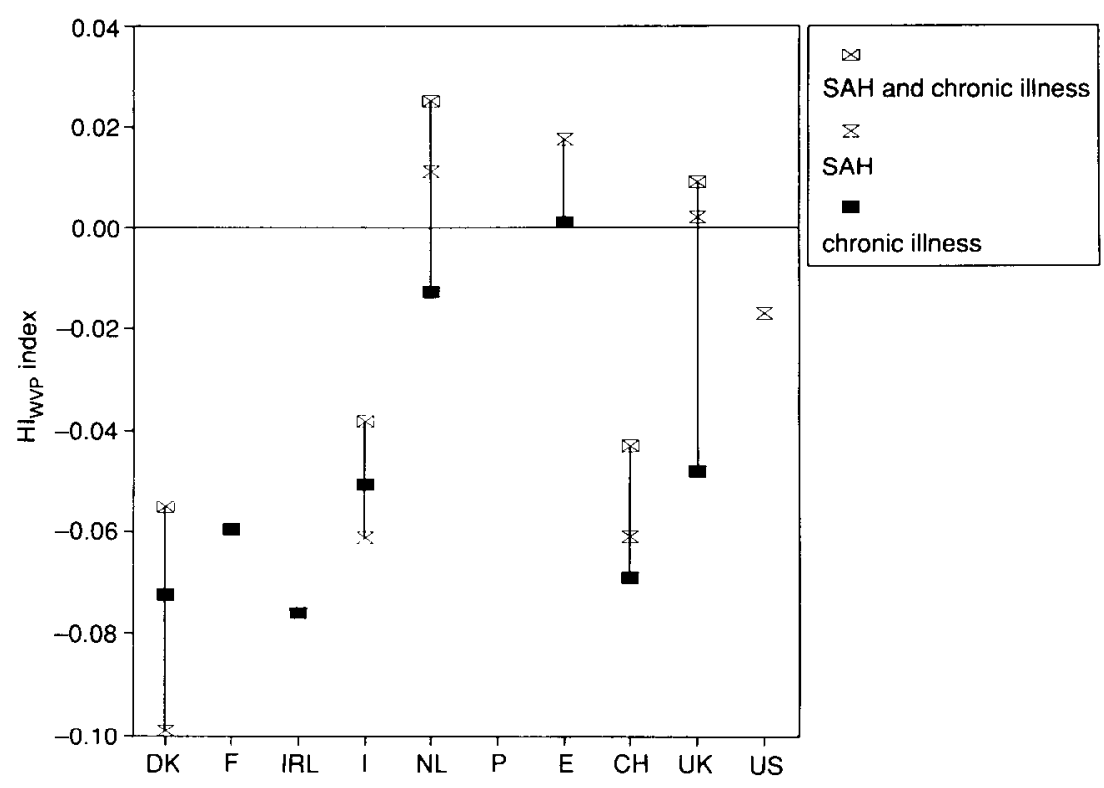

Fig. 4. $\mathrm{HI}_{\mathrm{wvP}}$ indices for various morbidity indicators.

inpatient days (or, in some cases, spells) have been weighted by their average cost. Except in situations where there was a clear difference between public and private sectors in the quality of care delivered (i.e. in the likely improvements in health status), the same unit cost was used for both sectors.

\section{Empirical results}

The empirical results reported here are based on variations of eq. (3) estimated on samples comprising adults only. ${ }^{10}$ In all sets of results five income groups were used, and demographic variables were also entered in the equations (five age groups and a gender dummy). Where several morbidity indicators were available, results were obtained for each indicator separately, as well as for all morbidity indicators combined.

\subsection{Inequity indices}

Fig. 4 shows the values of the $\mathrm{HI}_{\mathrm{WvP}}$ index when self-assessed health and

${ }^{10}$ The full results are reported in Van Doorslaer, Wagstaff and Rutten (1993). 
chronic sickness are used as indicators of need. The most striking feature of the chart is that in all but four cases where need is proxied by self-assessed health or chronic sickness, the index values are negative. Only in the Spanish case is the $\mathrm{HI}_{\mathrm{WVP}}$ index for the chronic indicator positive (and even then only marginally so), and only in the cases of Spain, the Netherlands and the U.K. is the index positive for the self-assessed health indicator. ${ }^{11}$ Taken at face value the results in fig. 4 imply that if there is any inequity in the delivery of health care in these countries, it favours the less well-off. However, as we emphasize below, there is good reason to be wary about jumping to such a conclusion. Another noteworthy feature of fig. 4 is that the ranking of the six countries for which there is information on both morbidity indicators is virtually the same irrespective of which of the two indicators is chosen: (in descending order) Spain, the Netherlands, the U.K., Switzerland, Italy and then Denmark.

One reason for not reading too much into the results in fig. 4 is that it may well be the case that inequalities in health exist amongst the chronically sick and amongst those who perceive their health to be not good [O'Donnell and Propper (1991a)]. Fig. 4 also reveals that in all countrics the $\mathrm{HI}_{\mathrm{WvP}}$ index is larger when the self-assessed health and chronic sickness indicators are used simultaneously than when each is used alone. The implication is that failure to take into account the extent of pro-rich inequalities in health within morbidity categories tends to result in an underestimate of the extent of inequity in the delivery of health care that favours the well-off, or an overestimate of the extent to which it favours the less well-off.

Indeed, it seems highly unlikely that all such inequality is taken into account simply by including self-assessed health and chronic sickness simultaneously. Using data from the British Health and Lifestyle Survey, O'Donnell and Propper (1991a) find that amongst persons reporting chronic illness those in the lower income groups were more likely than their betteroff counterparts to suffer from both more than one condition and relatively serious conditions, such as heart disease, angina and heart attack, and arthritis and rheumatism. By contrast those in the lower income groups were least likely to suffer from less serious complaints such as skin disease, eczema and dermatitis, and migraine and chronic headache. Similar results are reported for the Netherlands in Van Doorslaer et al. (1993). This suggests that future work in this area ought to incorporate information not simply on whether chronic illness is reported, but rather on the number and type of chronic conditions reported.

Some results for Denmark reported in Christiansen (1993) indicate how

\footnotetext{
${ }^{11}$ The fact that the index is positive for Spain when the chronic ill-health indicator is used alone may reflect the nature of the indicator. Unlike the chronic ill-health indicator used in the analyses of the other seven countries, the Spanish indicator is based on information covering only a handful of chronic conditions.
} 
sensitive the $\mathrm{HI}_{\mathrm{Wvp}}$ index is to the amount of information used in its calculations. When chronic sickness alone is used to calculate the index, its value is -0.072 . When, in addition to chronic sickness, self-assessed health is included, the index rises to -0.055 . Finally, when the number of chronic conditions is used (instead of simply whether or not the individual suffered from chronic sickness), and the number of activity-restricted days is included in addition to self-assessed health, the $\mathrm{HI}_{\mathrm{WvP}}$ index rises to -0.031 . It sccms highly likely in the light of the British and Dutch results noted above that if information on the type of chronic condition were to be included as well, the index would become larger and might even become positive.

The upshot of all this is that the $\mathrm{HI}_{\text {wrp }}$ indices in fig. 4 appear to understate the degree of any inequity favouring the well-off and overstate the degree of any inequity favouring the less well-off. Indeed, it is quite possible that the negative $\mathrm{HI}_{\mathrm{WvP}}$ values are simply due to a failure to take into account the full extent of inequalities in health across income groups. What is implied by the discussion above is that incorporating more detailed information on morbidity is most unlikely to cause any positive $\mathrm{HI}_{\mathrm{WvP}}$ values to become negative. This suggests that any inequity in the delivery of health care in Britain, Spain and the Netherlands does, indeed, favour the well-off, but that this may be true of other countries as well.

\subsection{Test results}

Another reason for not reading too much into the results reported in fig. 4 is that the index values are small in absolute value. This suggests that any inequity might not be too large to worry about. A sufficient - but not necessary - condition for the $\mathrm{HI}_{\mathrm{WvP}}$ index to be zero is that the regression coefficients in models such as those in eqs. (2) and (4) are the same across all income groups.

Rather than report the LR statistics for all the various specifications estimated on all eight datasets, table 5 reports the LR tests statistics and the associated $\mathrm{HI}_{\mathrm{WvP}}$ values only for the most general specification for which the LR statistic was reported. These are therefore the specifications that capture as much income-related variation in morbidity as possible. The table reports the LR test statistics for the first and second parts of the two-part model separately, as well as those for the combined model.

Surprisingly, perhaps, the probability of seeking care - holding age, gender and need constant - does not appear to depend on income. One exception is Denmark, but this result may have been caused partly by inadequate income data. Income does, however, affect the amount of care received by those who use at least some health care: in all countries except Denmark and Switzerland the LR test statistic exceeds the $1 \%$ critical value of the chisquared distribution. Our evidence suggests, therefore, that amongst thosc 


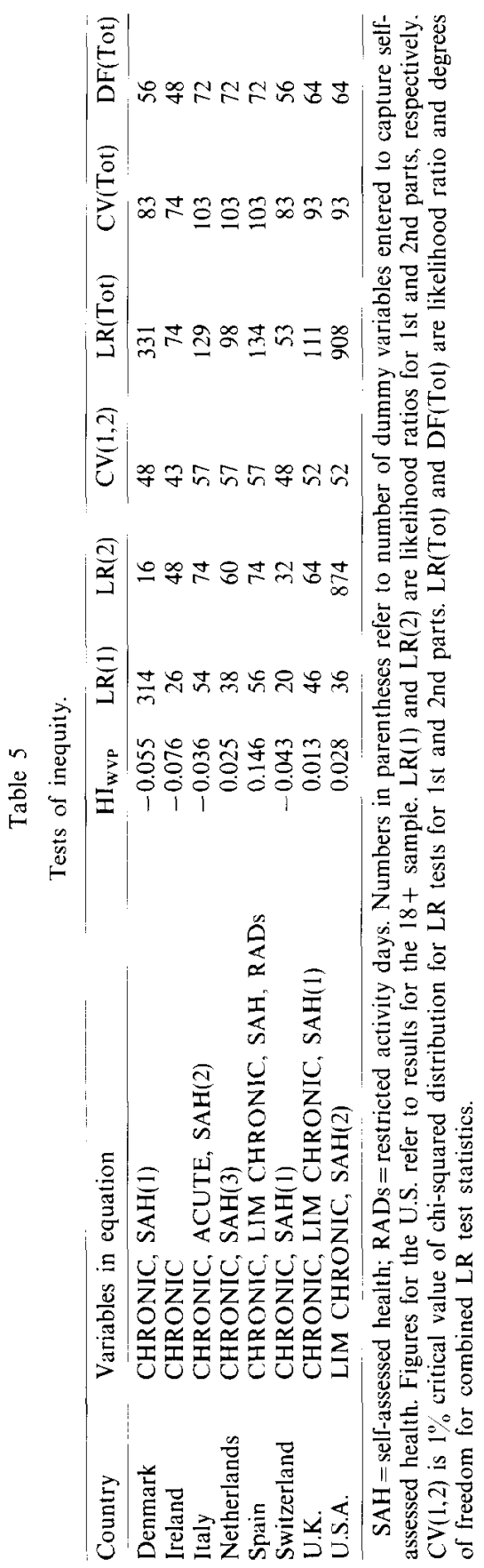


who have entered the health care system, persons in equal need are not being treated equally. Indeed, the LR statistics for the two-part model as a whole (i.e. taking into account the effect of income on both the decision to seek care and the amount of resources received once contact has been made) suggest that inequity exists in the delivery of health care in all countries except the Netherlands and Switzerland. In these two countries the test statistic falls below the $1 \%$ critical value. In the cases of Denmark, Italy, Spain, the U.K. and the U.S., the LR test statistic exceeds the critical value, suggesting that overall in these countries there is unequal treatment for equal need and that this inequity is income-related, whilst in the Irish case the LR statistic is exactly equal to the $1 \%$ critical value. According to the $\mathrm{HI}_{\mathrm{WvP}}$ values, this inequity appears, on balance, to favour the better-off in Spain, the U.K. and the U.S. In the context of the U.S. it is worth noting that when the elderly are excluded from the sample, the LR test statistic is still extremely large but the $\mathrm{HI}_{\mathrm{WvP}}$ value indicates that this inequity appears to favour, on balance, the worse-off [cf. Gottschalk and Wolfe (1993)]. Whether the results obtained for other countries are similarly sensitive to the exclusion of the elderly - perhaps due to the inadequacy of income as a measure of economic well-being - remains to be seen. The $\mathrm{HI}_{\mathrm{WvP}}$ values, coupled with the LR test statistics, suggest that any inequity in Denmark and Italy favours the worse-off. However, the earlier comments about the sensitivity of the $\mathrm{HI}_{\text {WVP }}$ values to the information included on need should be borne in mind. It is evident from the LR test results reported in table 5 that the most decisive rejection of the null hypothesis of no income-related inequity is in the case of the U.S. ${ }^{12}$

\section{Summary and Conclusions}

The objective of this paper was to establish any cross-country differences in the extent to which persons in equal need of health care are treated the same, irrespective of their income. Two approaches were used. The first, which seeks to establish the extent of any inequity, entails an analysis of variations across income groups in standardized values of imputed medical expenditures. This approach asks, in effect, 'how much would each income group have received on average if its age structure and morbidity levels had been the same as those of the population at large?' If the better-off receive a larger expenditure having controlled for need and demographic factors, one concludes that inequity exists and it favours the better-off. The second approach, which seeks simply to test for inequity, involves a regression

\footnotetext{
${ }^{12}$ This is despite the fact that the U.S. does not have the largest $\mathrm{HI}_{\text {wvp }}$ value. The apparent paradox is explained by the fact that the U.S. standardized expenditure concentration curve crosses the diagonal. The LR test statistic for the 18-65 sample is also much higher than any of the LR values reported for any of the other countries.
} 
analysis of imputed expenditures to test the hypothesis that the relationship between the amount of medical care received and the determinants of utilization (morbidity, age and gender) is the same for all income groups. This is equivalent to testing the hypothesis that imputed expenditures do not vary across income groups within each age-sex-morbidity category.

The results obtained using the first method are somewhat sensitive to the choice of health indicators. When several health indicators are included simultaneously, the standardized medical expenditure distributions are less pro-poor, or more pro-rich, than when only one indicator is included at a time. This suggests that inequalities in morbidity exist within morbidity categories. This is taken into account by the multiple-indicator standardization results. What is not taken into account in these results is the fact that the worse off appear to be not only more likely to suffer from a chronic illness, but also more likely to suffer from several chronic illnesses at the same time, as well as from relatively serious illnesses. The inequity index values reported therefore almost certainly overstate any inequity favouring the less well-off and understate any inequity favouring the well-off. This implies that in countries where inequity favouring the well-off was detected and the null hypothesis of no inequity was rejected (Spain, the U.K. and the U.S.), pro-rich inequity almost certainly exists. A caveat here is that when the elderly are excluded from the U.S. sample, the inequity actually appears to favour the poor. However, as indicated above, it has not been possible yet to determine whether the results for the other countries are similarly sensitive to the exclusion of the over-65s.

The regression tests, which were undertaken for the most general model specifications only, suggest that income-related inequity exists in five of the eight countries, notably Denmark, Italy, Spain, the U.K. and the U.S. The test statistic for the Irish sample was identical to the $99 \%$ critical value of the chi-squared distribution, whilst the tcst statistics for the Dutch and Swiss samples fell below the relevant critical values. The rejection of the null hypothesis of no inequity was decisive in the Danish sample and in both U.S. samples, but much less decisive in the British, Italian and Spanish samples.

It would clearly be unwise, in view of the sensitivity of the index values to the amount of information used in its calculation, to attempt to draw firm conclusions about the extent to which any cross-country differences in inequity can be attributed to differences in health care delivery systems. Some tentative conclusions do, however, emerge. First, our results suggest strongly that persons in equal need in the U.S. are not treated the same, though - somewhat surprisingly - whether this inequity, on balance, favours the better-off or worse-off depends on whether one examines only the under$65 \mathrm{~s}$ (in which case the inequity appears to favour, on balance, the worse-off) or the entire adult population (in which case the inequity favours, on balance, the better-off). Second, there appears to be inequity favouring the 
well-off even in some countries where public cover is universal and comprehensive, notably Spain and the U.K. In both countries this appears to be due, at least in part, to the above-average private expenditures of the betteroff. Third, it appears that he'dlh care systems which do not have universal and comprehensive public cover are not necessarily those with the highest degree of inequity. Indeed, in both Switzerland and the Netherlands, where public cover is limited, the null hypothesis of no income-related inequity could not be rejected at the $1 \%$ level. Refinements to the empirical analysis in future work, including at least the use of richer information on need, is necessary to verify the robustness of these findings.

\section{Appendix: Authors and affiliations}

Samuel Calonge, University of Barcelona, 08034 Barcelona, Spain.

Terkel Christiansen, Odense University, 5320 Odense M, Denmark.

Michael Gerfin, University of Bern, 3012 Bern, Switzerland.

Peter Gottschalk, Boston College, Chestnut Hill, MA 02167, U.S.

Richard Janssen, Limburg University, 6200 MD Maastricht, Netherlands.

Claire Lachaud, University of Lyon 1, 69622 Villeurbanne cedex, France.

Robert E. Leu, University of Bern, 3012 Bern, Switzerland.

Brian Nolan, Economic and Social Research Institute, Dublin 4, Ireland.

Owen O'Donnell, University of York, York YO1 5DD, U.K.

Pierella Paci, City University, London EC1V 0HB, U.K.

João Pereira, National School of Public Health, 1699 Lisbon Codex, Portugal.

Carlos Gouveira Pinto, Lisbon Technical University, 1200 Lisbon, Portugal.

Carol Propper, University of Bristol, Bristol BS8 1TH, U.K.

Joana Reñé, SOIKOS, 08028 Barcelona, Spain.

Lise Rochaix, University of Lyon 1, 69622 Villeurbanne cedex, France.

Marisol Rodriguez, University of Barcelona, 08034 Barcelona, Spain.

Frans Rutten, Erasmus University, 3000 DR Rotterdam, Netherlands.

Richard Upward, University of Bristol, Bristol BS8 1TH, U.K.

Eddy Van Doorslaer, Erasmus University, 3000 DR Rotterdam, Netherlands. Adam Wagstaff, University of Sussex, Brighton BN1 9QN, U.K.

Barbara Wolfe, University of Wisconsin, Madison, WI 53706, U.S.

\section{References}

Blaxter, M., 1989, A comparison of measures of inequality in morbidity, in J. Fox, ed., Health inequalities in European countries (Gower, Aldershot). 
Christiansen, T., 1993, Equity in the finance and delivery of health care in Denmark, in: E. van

Doorslaer, A. Wagstaff and F. Rutten, eds., Equity in the finance and delivery of health care: An international perspective (Oxford University Press, Oxford).

Collins, E. and R. Klein, 1980, Equity and the NHS: Self-reported morbidity, access and primary care, British Medical Journal 281, 111-115.

Culyer, A.J., E. Van Doorslaer and A. Wagstaff, 1992a, Comment: Utilisation as a measure of equity, Journal of Health Economics 11, 43-98.

Culyer, A.J., E. Van Doorslaer and A. Wagstaff, 1992b, Access, utilisation and equity: A further comment, Journal of Health Economics 11, 207-210.

Davis, K., 1993, Equity and health care policy: The American experience, in: E. Van Doorslaer, A. Wagstaff and F. Rutten, eds., Equity in the finance and delivery of health care: An international perspective (Oxford University Press, Oxford).

Godfrey, L., 1988, Misspecification tests in econometrics (Cambridge University Press, Cambridge).

Gottschalk, P. and B. Wolfe, 1993, Equity in the finance and delivery of health care in the United States, in: E. Van Doorslaer, A. Wagstaff and F. Rutten, eds., Equity in the finance and delivery of health care: An international perspective (Oxford University Press, Oxford).

Hooijmans, E.M. and F.F.H. Rutten, 1984, The impact of supply on the use of hospital facilities: Differences between high and low income groups, Acta Hospitalia 2, 41-48.

Iachaud, C. and L. Rochaix, 1993, Equity in the finance and delivery of health care in France, in: E. Van Doorslaer, A. Wagstaff and F. Rutten, eds., Equity in the finance and delivery of health care: An international perspective (Oxford University Press, Oxford).

Le Grand, J., 1978, The distribution of public expenditure: The case of health care, Economica $45,125-142$.

Le Grand, J., 1982, The strategy of equality: Redistribution and the social services (Allen \& Unwin, London).

Le Grand, J., 1991, The distribution of health care revisited: A commentary on Wagstaff, Van Doorslaer and Paci, and O'Donnell and Propper, Journal of Health Economics 10, $239-245$.

Manning, W., C.M. Morris, J.P. Newhouse et al., 1981, A two-part model of the demand for medical care: Preliminary results from the RAND health insurance study, in: J. van der Gaag and M. Perlman, eds., Health, economics and health economics (North-Holland, Amsterdam).

Mooney, G., Equity in health care: Confronting the confusion, Effective Health Care 1, 179-185.

Mooney, G., J. Hall, C. Donaldson and K. Gerard, 1991, Utilisation as a measure of equity: Weighing heat?, Journal of Health Economics 10, 475-480.

Mooney, G., J. Hall, C. Donaldson and K. Gerard, 1992, Reweighing heat: Response to Culyer, van Doorslaer and Wagstaff, Journal of Health Economics 11, 199-205.

Newhouse, J.P., W.G. Manning and C.M. Morris, 1981, Some interim results from a controlled trial of cost sharing in health insurance, New England Journal of Medicine 305, 1501-1505.

O'Donnell, O. and C. Propper, 1991a, Equity and the distribution of U.K. National Health Service resources, Journal of Health Economics 10, 1-19.

O'Donnel1, O. and C. Propper, 1991b, Equity and the distribution of U.K. National Health Service resources, A reply, Journal of Health Economics 10, 247-250.

Pereira, J. and C.G. Pinto, 1993, Equity in the finance and delivery of health care in Portugal, in: E. Van Doorslaer, A. Wagstaff and F. Rutten, eds., Equity in the finance and delivery of health care: An international perspective (Oxford University Press, Oxford).

Puffer, F., 1986, Access to primary care: A comparison of the U.S. and U.K., Journal of Social Policy 15, 293-313.

Van Doorslaer, E., A. Wagstaff and R. Janssen, 1993, Equity in the finance and delivery of health care in the Netherlands, in: E. Van Doorslaer, A. Wagstaff and F. Rutten, eds., Equity in the finance and delivery of health care: An international perspective (Oxford University Press, Oxford).

Van Doorslaer, E., A. Wagstaff and F. Rutten, eds., 1993, Equity in the finance and delivery of health care: An international perspective (Oxford University Press, Oxford).

Van Vliet, R. and W. van de Ven, 1985, Differences in medical consumption between publicly and privately insured in the Netherlands: Standardization by means of multiple regression. Paper presented to International meeting on Health Econometrics of the Applied Econometrics Association, December 16-17, Rotterdam. 
Wagstaff, A., E. Van Doorslaer and P. Paci, 1991a, On the measurement of horizontal equity in the delivery of health care, Journal of Health Economics 10, 169-205.

Wagstaff, A., E. Van Doorslaer and P. Paci, 1991b, Horizontal equity in the delivery of health care: A reply, Journal of Health Economics 10, 251-256.

Wagstaff, A., E. Van Doorslaer, et al., 1992, Equity in the finance of health care: Some international comparisons, Journal of Health Economics 11, 361-387. 